https://doi.org/10.48009/1_iis_2010_678-688

\title{
MITIGATING RISK IN A HIGH UNCERTAINTY AVOIDANCE CULTURE - AIR TRAFFIC CONTROL
}

\author{
Darlene Ann Drazenovich, Robert Morris University, Ddrazenovich1@ comcast.net \\ Robert Joseph Skovira, Robert Morris University, skovira@ rmu.edu
}

\begin{abstract}
The essay is a report of research carried out in an air traffic control environment. It is a description and analysis of the ethnosemantics of air traffic controllers and their social cultural environment of information flows and uses of information. Using Hofstede's theory of cultural dimensions, specifically his theory of uncertainty avoidance and Hall's theory of culture as a communicational context, the paper analyzes uncertainty avoidance in a high reliability organization, air traffic control, from the perspective of mitigating risk.
\end{abstract}

Keywords: Air Traffic Control, Uncertainty Avoidance, Risk Mitigation, Information Systems

\section{INTRODUCTION}

"Double Trouble: Two Children took to JFK Controls ... Two kids directed air traffic on consecutive days in February," reports CNBC on March 30, 2010 [4]. CNN reports, "Air traffic controller, supervisor on leave after kids talk to pilots" [1]. On April 26, 2010, the Bloomberg Business Week reports on, "The NYC Air Traffic Control Kid and Aviation Professionalism" [2]. This fantastical and unbelievable news hit the world stage in print, video, audio and by word of mouth. An air traffic controller brought children to work on February $16^{\text {th }}$ and $17^{\text {th }}$ and permitted the children to talk to pilots [4]. According to the news reports, the FAA finds the behavior unacceptable for an air traffic controller and expressed that the controller's lapse in judgment violated FAA polices and professional conduct $[1 ; 2]$. The Air Traffic Controllers' National Union stated that they, "do not condone this type of behavior ...[i]t is not indicative of the highest professional standards that controllers set for themselves and exceed each and every day in the advancement of aviation safety" [4].

The news reports discuss this incident and air traffic control (ATC) in such terms as professionalism, conduct, standards, policies, safety, technology, communications, reliability, highly supervised, and caliber of work force. The terms are indicative of just some of the components in and aspects of an ATC information system. People, content, processes and relationships are component parts of the ATC information system. These components and aspects help to form the basis for risk mitigation strategies and pathways to safety in the ATC culture.

\section{THEORETICAL BACKGROUND FRAMING THE STUDY}

People live and work within social-cultural complexes, multilayered affairs [24] of shared systems of meanings [35], sharing situations [19], through affordances and constraints of practices and vocabularies [5]. This is metaphorically an infoscape [33], which is a contextualizing environment of informing systems (people, content, processes and relationships) and the forms and uses of information.

A multilayered social-cultural environment consists of social-cultural frames [16], which are a configuration of shared systems of meanings or theories, practices and situations. Frames are perspectives of valuing. Every social-cultural environment consists of informizing and normizing frames. An informizing and normizing frame is a frame which informs and normalizes behavior in terms of theories in play in practices, vocabularies, and situations. Frames have social-cultural dimensions [24] as circumstances of events, affairs and actions.

A fundamental dimension of any social-cultural environment is the avoidance of uncertainty [24]. Hofstede's theory is that social-cultural groups develop over time ways and means (practices and vocabularies) of dealing with ambiguous or uncertain situations. Social-cultural groups' members act and make decisions, and have policies and rules for acting and deciding, to avoid the undesirable and undesired results of uncertain situations. Social-cultural environments or situations which are highly 
structured and restrictive are high uncertainty avoiding environments or situations. Low uncertainty avoidance environments are less rigid, more open, less structured.

Every social-cultural environment is a communicational environment [19], which allows or restrains situationally the use of vocabularies (and logic) by an implicit or explicit referencing of the normalizing patterns, semantic units [9] of the socialcultural environment. An information system is a structured ordering of a communicational environment. A high context of communication relies on a shared sense of affairs, and situations. A low communication context spells out, perhaps in rigid definitions and rules, the acceptable sense of affairs and situations. An implicit reference by vocabularies of their informational ground is Hall's high context of communication and an explicit reference is Hall's low context. The game of uncertainty avoidance is a game of low communicative context.

Situations and their circumstances [19] are expressions of boundaries of events and affairs, allowing or restraining practices, routines dealing with actions and their ends. Actions intend (attend to) ends-in-view or purposes. Situations are also communicative contexts. There are formal and informal situations. At the centers of situations are people who work out (and out of) takes [27;6] which are realizations [5] of high or low communicative contexts [19]; the contexts are the complex multiplicities of situations and their circumstances covered by shared systems of meanings. Situations become bounded spaces for action avoiding uncertainty by becoming policy- and rule-driven. An information system is a structured way of maintaining such bounded action spaces in an uncertain and risky environment.

Practices are normized behaviors, actions and language allowed or restrained according to the endsin-view of the situations [5]. Practices, rituals and symbols, mark situations [27]. Practices mark situations because situations mark them as appropriate or inappropriate behaviors; they either work or do not work toward or achieve the situational ends. Practices become keys to playing the game of uncertainty avoidance.

\section{Dimensions of National Culture}

Hofstede's research showed that "cultural differences between modern nations could be meaningfully measured and ordered along a discrete set of dimensions, representing different answers to universal problems of human societies" [21, p. 883; 24]. His cultural 'dimensions' paradigm includes four dimensions; power distance, uncertainty avoidance, individualism-collectivism, and masculinity-femininity $[21 ; 24]$. He later added a fifth dimension of long-term versus short-term orientation [21;24].

\section{High Reliability Organizational Culture}

High reliability organizations (HROs) are characterized by nearly error-free operations for long periods and management of unexpected sequences of events [30]. HRO's are mandated to "do everything possible to avoid altogether certain kinds of negative outcomes" notes Klein, Bigley, and Roberts [26, p. 772]. "HRO's must perform at high temp for sustained periods of time and maintain the ability to do so repeatedly without damaging themselves or others" $[26$, p. $772 ; 30]$. When danger threatens or emergencies occur, HRO's cannot "stop performing until the danger passes, the error rectified" $[26, \mathrm{p}$. $772 ; 30]$. To identify an organization as a HRO, Roberts suggests asking the question, "How often could this organization have failed with dramatic consequences?" [30, p. 101-102]. If the answer is yes, that the organization could have failed thousands of times with dramatic consequences, then the organization is highly reliable [30]. Roberts categorizes air traffic control (ATC) as a HRO and reports on "how they maintain safe and reliable operations under hazardous conditions" $[30$, p. 102 ; 17]. In the ATC environment, weather, pilot or controller error and emergencies can cause unexpected sequences of events $[7 ; 8 ; 30]$. ATC, as an HRO, must manage complexity, reduce risk probabilities, and accept the cost for reducing risk [18; 30]. Grabowski and Roberts found that "decision making in HROs occurs under conditions of uncertainty, stress, and less than perfect information" [18, p. 155]. In HRO's small errors can propagate into grave consequences" state Grabowski and Roberts, therefore managing risk is vital for these organizations $[17$, p. 706$]$.

\section{Ethnographical Studies of IS Cultures}


Ethnography (consisting of fieldwork, analysis of the fieldwork, and the wrting of a group's social-cultural narrative) is an appropriate and viable method for the study of information system (IS) culture $[3 ; 7 ; 8 ; 25$; 31]. Studies using ethnographic methods also reflect the appropriateness of ethnography in the analysis of the air traffic control culture $[3 ; 7 ; 8 ; 25]$. One ethnographic study resulted in the design of a new user interface system for air traffic controllers [3]. Another study used ethnography as a method for information system design in air traffic control [25]. Another study used an ethnographic method of inquiry to examine the use of radar data in air traffic control [7]. An ethnographic method was used in another analysis to examine Hall's context of communications in air traffic control $[8 ; 19]$. These studies echo the applicability of ethnographic methods in the study of information systems and air traffic control as an information system.

\section{Purpose and Focus of Paper}

The paper is a brief report describing an analysis of air traffic controllers as a social group and the shared system of meanings, practices, and situations constituting the group's "culture." It approaches this analysis through the theoretical lens of Hofstede's 'dimensions' paradigm, a model for analyzing dimensions of national culture. The purpose of this paper is to analyze uncertainty avoidance in a high reliability organizational culture - air traffic control, from the perspective of managing risk.

\section{METHODOLOGY}

The exploratory research reported here utilizes a qualitative method of discovery - an ethnographic approach, $[34 ; 35 ; 36]$ to investigate the_cultural meaning of events, language, activities, and shared mental models for employees at an Air Route Traffic Control Center in Virginia. The ethnographic study relied predominately on observations, interviews, vignettes, and artifacts. The Center's management assigned two FAA employees to escort and assist the researcher throughout the data collection process. The researcher took advantage of having two FAA insiders and relied on them as academic informants.

The researcher is visually impaired and conducted the observation phase of the research in the dark, you can say by Braille. During an orientation of the control room, an FAA employee had to hold the researcher's arm and lead her through the control room to the controller's station. The control room was extremely dark with the only light coming from the radar displays, computers, and other displays throughout the control room. Even though this was the beginning of the data collection process, the researcher feared that this event might be the end for the research project. The Center personnel were very understanding of the visual disability and were extremely helpful and supportive of the researcher in successfully getting through the next several months of data collection. The researcher observed participants in the control room for six periods, in each instance, spending two or more hours observing the controllers in action. An FAA employee led the researcher to the seat next the controller to be observed. The researcher could not move until an FAA employee came to retrieve her. Thus, the researcher experience firsthand, being glued to the air traffic controller's position until properly relieved by the supervisor. The researcher was not permitted to, and did not talk to pilots on the radio, and did not control or track aircraft. However, the observer did sit next to controllers and was able to view all of the air traffic control equipment, and displays. The researcher listened to pilots and controllers' conversations by using a controller's headset and directly observed all controller actions. The FAA personnel gave very clear instructions to the researcher not to touch any equipment and not to press the talk button on the headset. They said 'if you press the talk button, the controller would get up and walk away and leave you to control the sector.' Well, I knew the FAA would never allow me to control the sector, but they scared me enough that I did not touch anything.

The researcher met with the FAA insiders following each period of observation to discuss what the researcher experienced and observed. The FAA employees provided context and meaning for the observations. The researcher also observed automation, maintenance, and national airspace system (NAS) operations' manager (NOM) technicians in their natural settings. The researcher conducted 20 controller and supervisor interviews and 4 technician interviews. The researcher asked the controllers and supervisors 14 questions and presented a subset of these questions to the technicians, which covered a range of topics about sources of information and data and the type of equipment controllers use to manage air traffic, 
convergence of information and data, radio frequency interference and the controllers' responsibilities.

\section{DIMENSIONS OF CULTURE - UNCERTAINTY AVOIDANCE}

The term 'uncertainty avoidance' has its roots in earlier organizational sociology works such as James G. March and his colleagues' studies on organizational ambiguity and choice $[24 ; 28]$. Employees, and the organizations they belong to, manage ambiguity by avoiding it [28]. In utilizing the term ambiguity, March and Olsen refer to four major types of opaqueness in organizations; ambiguity of intention, ambiguity of understanding, ambiguity of history, and ambiguity of organization [28]. The opaqueness in the air traffic control culture, that is appropriate for this study, surrounds ambiguities of understanding and organization.

Organizations can experience ambiguity in their understanding of technology and interpretation of their environment [28]. The ATC environment encompasses massive amounts of complex and interdependent technologies, deployment of new and innovative technologies, and the ever-changing air traffic environment, all of which can lead to ambiguity and uncertainty in the organization $[7 ; 8$; 30]. In terms of ambiguity of organizations, individuals vary in their decision-making from timeto-time and individual-to-individual, resulting in uncertain and changing decisions and patterns of participation [28]. March and Olsen suggest that ambiguity is a dominant factor in decision-making in some organizations, such as public organizations and organizations with a changing environment [28]. ATC is a public (governmental) organization and a changing environment exists at the very core of their operations.

Hofstede describes uncertainty avoidance as "[t]he extent to which members of a culture feel threatened by uncertain or unknown situations. One of the dimensions of national culture (from weak to strong)" [24, p. 263]. Hofstede explains that, "[e]xtreme uncertainty creates intolerable anxiety" and explains that societies have developed ways, in the technology, religion, and law domains, to alleviate these anxieties [24, p. 110],

Hofstede developed an uncertainty avoidance index (UAI), based on his IBM research project, to measure the intolerance of ambiguity and the degree of uncertainty avoidance in a society or culture [24]. The UAI is based on answers to question related to rule orientation, employment stability, and stress [23; 24]. Hofstede's IBM study of 50 countries and three regions resulted in a range of UAI scores from 8 (lowest) to 112 (highest) [23; 24]. Low-UAI scores indicate a culture with fewer rules and a less desire to control results and outcomes $[10 ; 23 ; 24]$. These cultures have a higher tolerance for new and varied ideas and beliefs $[10 ; 23 ; 24]$. To eliminate or avoid the unexpected, high-UAI cultures tend to implement controls $[10 ; 23 ; 24]$. These cultures are more risk adverse and do not easily accept change [10;23;24].

\section{RISK MITIGATION AND UNCERTAINTY AVOIDANCE ANALYSIS RESULTS}

In Ellingson's research on managing risk from a cultural point of view, he refers to Hofstede's measure of UA in a culture as the culture's "appetite for risk" $[10$, p. $50 ; 23 ; 24]$. Ellingson utilizes Hofstede's UAI scale to analyze how different cultures, Japan and the United States, relate to risk based on the cultures' appetite for risk [10]. Japan and the United States were on the opposite ends of the UAI scale $[10 ; 23 ; 24]$. Ellingson considers lowUAI scores (United States) as risk takers and highUAI scores (Japan) as more risk adverse [10]. Hofstede stresses that countries take risks on either sides of the UAI scale (high and low) [23; 24]. HighUAI societies take known risks and low-UAI societies also take unknown risks $[23 ; 24]$. HighUAI cultures seek clarity, structure, and purity in rules, whereas low-UAI cultures are contented with chaos, ambiguity and convenience in relationship to rules [24]. Hofstede cautions not to equate uncertainty avoidance with risk avoidance [23].

This analysis utilizes a five step risk assessment methodology common to the study of risk mitigation; identifying context, risk identification, risk assessment, risk mitigatation and response, and risk monitoring and reporting $[10 ; 17]$.

\section{Context}

The goals, vision, strategies, and objectives of a high reliability organization define the context of the organization in terms of managing risk [10]. Whether the organization adopts long-term or shortterms objectives and strategies would differ 
depending on the culture [10]. In Japan, business objectives are long-term and U.S. corporate objectives are short-term $[10 ; 23 ; 24]$. Since Japan scores a high on Hofstede's uncertainty avoidance index (UAI), Ellingson recommends that risk managers "concentrate on the short-term obstacles (risks) in achieving the business objective" [10, p. 51; $23 ; 24]$. High UA cultures tend to value less uncertainty $[10 ; 23 ; 24]$. In Hofstede's study on cultural dimensions, the United States tends to score lower on the UAI focusing on the long-term corporate perspective, to compensate for short-term results $[10 ; 23 ; 24]$. On the surface, one might assume that United States' air traffic control organizations would assume the characteristics of a low uncertainty avoidance culture, since the United States tends to score lower on the UAI scale in Hofstede's studies $[23 ; 24]$. However, the research in the Air Route Traffic Control Center (ARTCC) in Virigina indicated that organizations as an information system, like high UA cultures, tend to value less uncertainty and focus on short-term obstacles (risks) to achieve their long-term goals [7; $8]$.

HRO's, including ATC, “are characterized by priorities of safety and reliability as goals" in order to enhance safe operations, noted Grabowski and

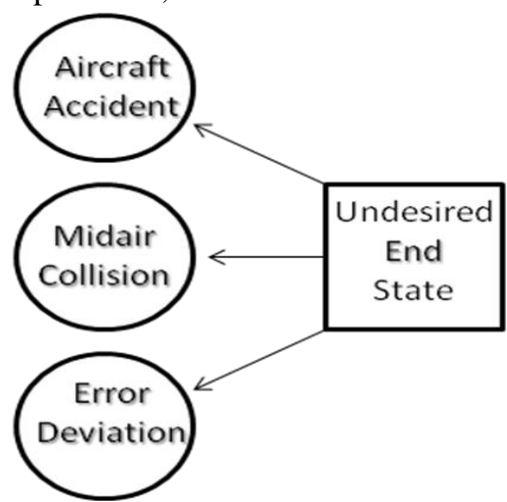

Figure 1. Model of ATC System End States

The flying public generally understands the terms aircraft accident and near midair collision. Pilot deviation refers to a pilot's actions in violation of ATC regulation. Thus, pilot deviation is not attributable to air traffic controllers. The terms operational error (OE) and operational deviation (OD) are not commonly understood outside of the ATC culture. FAA Order $7210.56 \mathrm{C}$ defines an OE in terms of not maintaining the minimum separation distance required between aircraft, and aircraft
Roberts [17, p. 706]. The research discovered that ATC establishes and defines their own safety goals by which to measure their own safety record $[7 ; 8$; $17 ; 10]$. HROs are strong safety cultures and "focus attention on procedures, policies, and reward structures" to reinforce their safety goals and mission [18, p. 157].

According to the research, the FAA stipulates the primary purpose of the ATC system "is to prevent a collision between aircraft operating in the system and to organize and expedite the flow of traffic, and to provide support for National Security and Homeland Defense" [13, p. 2-1-1]. The desired end state of an ATC system is to prevent an aircraft collision. The antecedent of the ATC system desired end state is an undesired end state. The FAA cites several types of incidents that hinder the ATC system in providing the safe and expeditious flow of air traffic. In the en route ATC environment studied in this analysis, the incidents that result in an undesired end states are: aircraft accident, near midair collision, pilot deviation, operational error, and operational deviation [15]. The researchers developed a model of desired and undesired end states of an ATC system based on the research at the ARTCC in Virginia as depicted in figure 1 .

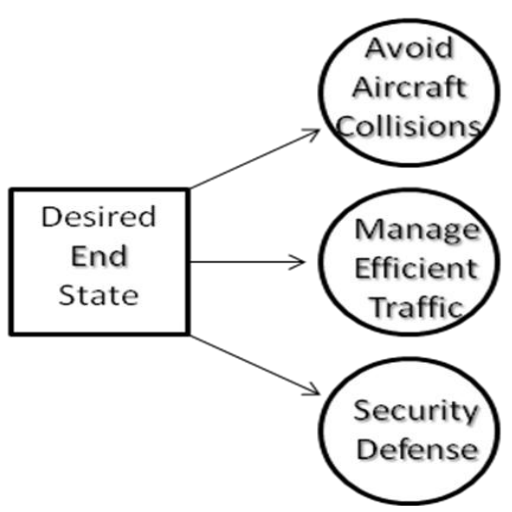

penetrating unauthorized airspace and violations of permissions and procedures $[15, \mathrm{p} .5-1]$. The FAA Order defines an OE, as applicable to the en route environment, "Less than $90 \%$ of the applicable separation minima results between two or more airborne aircraft, or less than the applicable separation minima results between an aircraft and terrain or obstacles" [15, p. 5-1]. Air traffic controllers indicated in interviews that they clearly understand their organization's vision, goals, and 
objectives. John says that from an overall management perspective, "we keep two planes from colliding. Based on the radar and the type of aircraft, we have horizontal separation and vertical separation." Matt elaborates that, "this has been our responsibility from the .65 manual "the safe, orderly and expeditious flow of aircraft through the NAS [national air space]' ... now, the new .65 manual revision as of September says I'm responsible for avoiding collisions." Rich says that, "controllers are responsible for separation for all aircraft regardless of manned, unmanned or type or size within our areas of jurisdiction ... known as our sectors to provide the safest and most efficient use of airspace."

\section{Risk Identification}

"Uncertainty avoidance leads to escape from ambiguity" explains Hofstede, "uncertaintyavoidance cultures shun ambiguity" [24, p. 148]. These cultures seek structure in their organizations so to make events predictable and clear to interpret [24]. Low UAI cultures tend to have a low acceptance of authority [10]. High UAI cultures tend to identify risk at higher levels of authority, such as managers, since these cultures have a high level of acceptance of authority [10]. The research discovered that the ATC culture has a hierarchical organizational structure and tends to have a high acceptance of authority, thereby placing this organization in the category of high uncertainty avoidance $[7 ; 8]$. The hierarchical structure of the ATC organization in Virginia includes the Center's Air Traffic Manager at the pinnacle of the structure, with five subordinate support managers and five subordinate air traffic control operational managers $[7, \mathrm{p} .62]$. The Virginia Center breaks down their organizational structure in more detail for the control room by day and night shifts [7, p. 63].

In HC systems Hall notes, "people in places of authority are personally and truly (not just in theory) responsible of the actions of subordinates down to the lowest man" [19, p. 113]. Responsibility in the ATC culture is not "difficult to pin down" and is not "diffused throughout the system" [19, p. 113]. The FAA ATC Order does not define absolute divisions of responsibilities within a sector, rather " $[t]$ he team, as a whole, has responsibility for the safe and efficient operation of that sector" [13, p. 2-10-1; 12]. In the event of an operational incident or accident, the FAA's intent is "not to hold the team accountable for the action of individual members" [13, p. 2-10-1;
12]. The Air Traffic Manager is the senior authority at an ATC facility and is personally responsible for the actions of subordinates [7;8]. At the ARTCC in Virginia, the manager involves the entire chain of command "down to the lowest man" in any operational error, accident or incident. The Air Traffic Manager at the ARTCC notes, "regardless of what goes on in this facility, we must maintain a steadfast and solid composure for all employees" [7, p. 43]. He said, "we must maintain focus and direction in accomplishing the Agency's goals, direction, policies, procedures, and training" $[7, \mathrm{p}$. 43].

At the ARTCC in Virginia, the high acceptance of authority and the clear delineation of responsibility down to the team level was evident in the observation phase of research, which was conducted on the control room floor. The researchers were able to determine the very detailed organization and team structures, and observed the teams performing their mission as stipulated in ATC orders and procedures.

\section{Risk Assessment}

High UAI cultures have a tendency to analyze and quantify risk in more detail. These cultures "tend to place more trust in the control mechanisms" and the employees and employers "trust each other to do the right thing without having to resort to controls to safeguard assets" [10, p. 52]. In virtual organizations with large scale interdependent systems, Grabowski and Roberts note that risk mitigation "involves developing trust and respect in working relationships and in developing the organization's ability to lean and adapt" [18, p. 154]. The research revealed that decentralization and interpersonal trust amongst employees are hallmarks of HROs, particularly in the ATC culture $[7 ; 8 ; 17 ; 18]$. The researchers discovered that trust amongst members of an HRO, such as ATC, is critical to maintaining the shared safety culture, thereby reducing risk and uncertainty $[7 ; 8 ; 17]$. The close proximity and face-to-face contact controllers experience with each other during their shift work at the ARTCC in Virginia, enables a shared culture of safety $[7 ; 8 ; 17]$.

The researchers' field notes from observations on the control room floor indicate that controllers work in close proximity to other in tight and confined work spaces. The controllers trust and depend on the other controllers in their team and the controllers in the adjacent sectors to reduce uncertainty and enable the 
smooth and efficient flow of air traffic and the avoidance of collisions.

Decision making in HRO's is carried out in "setting where organizational members are in close proximity to each other" and is characterized by, "consistency among beliefs, actions and decisions; avoidance of public, irrevocable, escalating decisions; limitations of leadership uncertainties; and collegial authority and decision patterns which overlay bureaucratic patterns" [18, p. 156].

\section{Risk Mitigation and Response}

HRO's develop procedures and policies, which are consistent with their organizational goals, to manage risk [17]. Cultures with high UAI scores prefer to conservatively manage uncertainty and risk, whereas low UAI cultures tend to accept increased risks [10]. To manage risk, countries like Japan depend on strict government regulations, whereas the United States and low UAI countries do not like strict rules and laws [10]. The research indicates that in an ATC high reliability organizational culture, highly technical regulations exist and detailed management directives explicitly direct procedures and processes [7; 18]. At the ATC facility in Virginia, the researchers found that ATC rules, policies, procedures, and training help to prevent uncertainty in the behavior of air traffic controllers and pilots [7; $8 ; 12 ; 13 ; 14 ; 29]$. The research at this ATC facility is Virginia revealed that ATC culture, as an HRO, depends on effective communication and employs redundancy in equipment, personnel and technology to realize their safety goals and achieve their desired end state $[7 ; 17]$.

Employees communicate to reduce uncertainty, thereby enabling a more predictable environment [17; $18 ; 30]$. Varied and effective communications in HROs, such as ATC, enable controllers to understand their roles, responsibilities, and relationships $[7 ; 8$; $17 ; 18]$. The organization's systems, to include risk mitigation and strategies can be improved through communications [18]. "In HROs, which already possess a culture of trust shared values, risk mitigating communications focus on enhancing the development of shared mental models among members of the organization" [18, p. 156].

ATC organizations assign "extraordinary degrees of responsibility and accountability to very low level employees" [30, p. 106; 7]. Organizations can mitigate risk by requiring employees "to take responsibility for their actions and to indicate when they are unsure about decisions, situations, or other individuals or groups in the system" [18, p. 157]. Communicating, specifying responsibilities and identifying ownership for outcomes helps to mitigate risk [18]. If an individual is uncertain explains Grabowski and Roberts, "that fact must be communicated and the uncertainty addressed. Otherwise, uncertainty and risk increase, which can pull the system apart" [18, p. 157].

In the dynamic environment of the ARTCC in Virginia, redundancy in personnel and the organizational structure enables operational slack, thus ensuring task performance $[7 ; 8 ; 17]$. The researchers found that the symmetrical structure in the ARTCC environment enables controllers and supervisors to regroup, restructure, and replace one another to react to increases in air traffic, weather conditions, emergencies, and personnel absences [7; 8 ; 17]. Controllers continually make rapid and intense decisions on the movement of air traffic [7; 17]. At the ATC facility in Virginia, controllers in the same and adjacent sectors are linked through job symmetry, dependence on accurate information, handover of air traffic and reciprocity $[7 ; 8 ; 17]$. These intense linkages lead to a culture of trust and joint problem solving, which in turn assists the organization in managing risk $[7 ; 8 ; 17]$.

"Technology helps to avoid uncertainty by nature" and "rules to try to prevent uncertainty in the behavior of other people" [24, p. 110]. The research revealed that the air traffic control culture at the ARTCC in Virginia, uses technology to help alleviate uncertainty by nature (weather and wind), and human nature (human error, errors in judgment, and slow reaction times). This technology includes surveillance radars, weather radars, collision avoidance systems, electronic flight plans systems, distance measuring equipment, radio beacon systems, flight projection systems, traffic management systems, and a myriad of other systems $[7 ; 17 ; 29]$. Computers, microwave radio systems, telephone lines and radar mosaic systems serve as redundancy in technology at the ARTCC in Virginia.

The researchers found that ATC organizations, like the facility in Virginia, manage risk through redundancy in equipment and technology. HRO's are technologically advanced even though they tend to rely on older equipment because it is proven technology [7; 30]. The ARTCC facility has a 
myriad of equipment from 30 to 40 year old technology to state-of-the-art technology just being deployed [7; 30]. As new technologies are installed and personnel are trained, the old technology serves as back-up or redundant systems for the Virginia Center [7; 30]. Technology in HROs can be so advanced that "errors can have far-reaching negative consequences" espouses Roberts, therefore operators need continuous training to "understand the capabilities of the technologies and how to respond to unexpected events" [30, p. 106; 7; 8; 26]. Detailed technical training and continual, repetitive training in the dynamic simulation lab at the ARTCC reinforces the safety culture of ATC.

Hall explains that transactions in $\mathrm{HC}$ "feature preprogrammed information that is in the receiver and in the setting, with only minimal information in the transmitted message" [19, p. 101]. The researchers discovered that preprogramming is a necessity for air traffic controllers at the ARTCC in terms of classroom and lab training, and phased onthe-job training.

To avoid baffling interactions, controllers at the ATC facility in Virginia receive training on hardware, software and human interaction with the technology so that they understand and manage the complexity of the technology $[7 ; 8 ; 30]$. The research revealed that ATC personnel and pilots preprogram content in their information systems to include electronic flight plans, weather data, symbols, automated procedures, and other data. FAA orders and regulations are the basis for preprogramming processes. The controller as the receiver accesses several different preprogrammed systems. The URET is preprogrammed with electronic flight progress strips, upper winds data, flight plans, host computer identification numbers (ID), aircraft identification numbers (ID), aircraft type, equipment, altitude, beacon code, and route [7, pp. 75-76].

At the ATC facility in Virginia, the controllers mainly use information preprogrammed into the information systems, procedures, and in the controllers. Data obtained from observations, interviews, orders, and procedures indicate that training and experience preprograms controllers. Therefore, the transmitted messages from people, content, processes, and context intersect at the controller's radar display. The controller can visualize and focus on all of the aircraft in the assigned sector. The controller sees a data block with specific symbols for each aircraft. The ATC culture adopted a specialized language to reduce ambiguity in their communications $[8 ; 30]$. Pilots and controllers receive training in their specialized and abbreviated language [8; 30]. Technicians and developers program the specialized language into information systems and software.

Hall suggests HC communication "is economical, fast, efficient, and satisfying; however, time must be devoted to programming ...[i]f this programming does not take place, the communication is incomplete" [19, p. 101]. During observations on the control room floor, the researchers found that the voice communications between controller and pilot must be economical, fast, and efficient in order for controllers to safely manage air traffic within their assigned sector. Pilots and controllers also learn specialized language to reduce ambiguity and uncertainty in their interactions $[7 ; 8 ; 30]$. In a very abbreviated language like code, the researchers discovered that pilot-controller voice and data communication include the transfer of such information as; the aircraft identification number, and model, type and manufacturer of aircraft, speed, direction, heading, altitude and a myriad of other information $[7 ; 8 ; 30]$.

\section{Reporting and Monitoring}

In risk reporting and monitoring, Ellingson recommends that a risk management department in an organization serve "as a coordinator or bridge across multiple functional silos and an objective party to validate the risks" $[10$, p. 53]. He also recommends that an organizations' management department own and monitor risks [10].

Strong safety cultures keep issues visible helping to reduce long incubation periods for undetected issues [18]. Safety cultures can reinforce their organizational goals through "oversight, checks and balances, and strong cultural norms" notes Grabowski and Roberts [18, p. 157]. These organizations by developing and reinforcing its cultural norms, and improving its systems over time [18].

Grabowski and Roberts warn that "poor performance can be fatal in HRO's" as evidenced by aviation accidents [17, p. 709]. The research revealed that HROs, such as the ARTCC in Virginia, that have a solid oversight program and have a strong system of 
checks and balances, are better able to maintain and grow their shared safety culture $[7 ; 8 ; 17]$.

\section{CONCLUSIONS}

The ATC culture, as an HRO, must be prepared to deal with complexity and respond to unexpected sequences of events in order to reduce the probability of risk [7; 8; 30]. In managing risk, ATC organizations must maintain sufficient resources, identify problems early, engage in detailed training and continuous practice, maintain redundancy in equipment and personnel, maintain excellent flows of communication, and encourage trust and shared value amongst employees $[7 ; 8 ; 30]$.

This paper described and analyzed the HRO culture of air traffic controllers and their social cultural environment of uncertainty avoidance. Information systems are more than just hardware and software, but also include people, processes, technology and software of the mind. This analysis demonstrated, through the theoretical lens of Hofstede's cultural dimensions' paradigm, that uncertainty avoidance in terms of managing risks is present in air traffic control information system.

Using Hofstede's cultural dimensions' model, the paper analyzed how the air traffic control system managed risk from its perspective as a high uncertainly avoidance culture. High uncertainty avoidance frames the way HROs, such as ATC, manage risk and achieve their desired end state. In order for an ATC system to achieve its desired end state - avoid collision, and organize and expedite air traffic - it employs various risk mitigation pathways. Those pathways include communications, rules, procedures and regulations, shared mental models and values, trust, redundancy and flexibility in organizational structure, redundancy in people and technology, and empowering employees.

Grabowski and Roberts concluded that good communication is necessary in HROs [18]. Open communications and the free flow of shared information "should lead to the development of shared mental models of the system, its hazards, and its warning systems" [18, p. 159]. A strong organizational culture and shared values are important for managing risk in ATC as an information system. It is important for ATC to reinforce their cultural norms and maintain highly structured organizational structures. Empowering air traffic controllers and their supervisors helps them to embrace their culture and respond to external and internal changes $[7 ; 8 ; 18]$.

Based on data collected from interviews, observations, academic research, FAA orders and procedures, the researchers developed a model depicting risk mitigation pathways an ATC culture utilizes to achieve its desired end state. The research indicates that any deviation from or a cut in one or more of the pathways could result in an undesired end state. Figure 2 depicts the model of risk mitigation pathways to an ATC system desired end state.

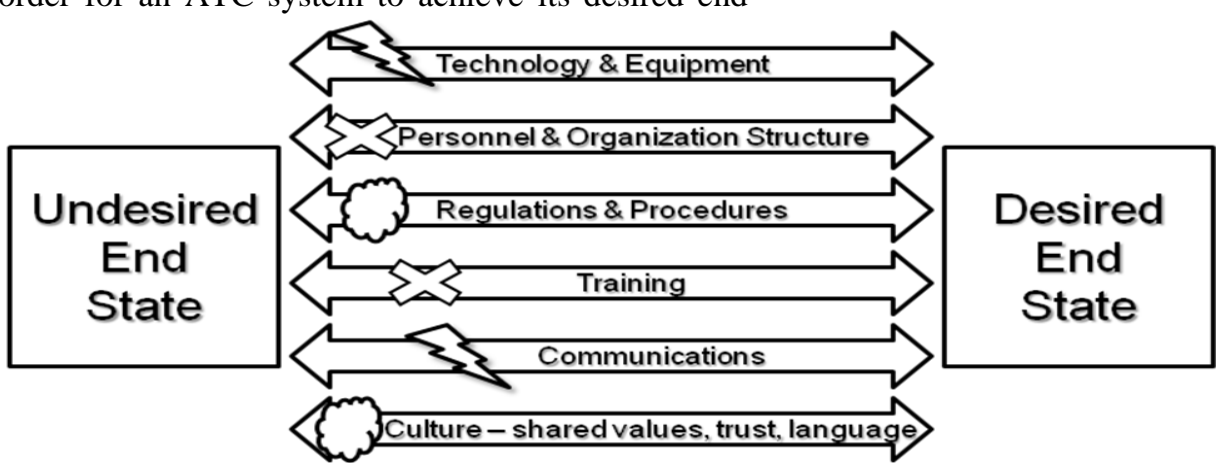

Figure 2. Model of Risk Mitigation Pathways to an ATC System Desired End State

The ATC information systems must mitigate risk to ensure for safety-of-life and safety-of-flight. HRO's, such as ATC, "must avoid errors or failures because the potential cost is unacceptable to society," notes Roberts, because when HROs fail, it shows up "on the front page headlines and in the eyes of the survivors or of the loved ones of the victims" [30, p. 112]. ATC organizations must pay the price of managing risk to maintain their culture of safety and high reliability $[7 ; 30]$. 
This paper contributes to the field of information systems by presenting air traffic control as a high reliability organization and how to manage risk in this high uncertainly avoidance culture. Researchers can benefit from the application of Hofstede's dimensions of culture paradigm, particularly the uncertainty avoidance dimension, presented in this paper, and utilize this analysis model to advance studies in the field information systems.

Air traffic control, as a high uncertainly avoidance culture, manages risk through use of communication, specialized abbreviated language, orders and procedures, regulations, redundancy in equipment, personnel and organizational structure, trust, employee empowerment, and shared values and mental models. This intricate information system along with its complex technologies and comprehensive risk management strategies, enable controllers to manage air traffic in a safe, efficient, and expedient manner, and avoid aircraft collisions.

\section{REFERENCES}

[1] Ahlers, M., Shin, J., and Candiott, S. (2010, March 3). Air traffic controller, supervisor on leave after kids talk to pilots. CNN Washington. Retrieved, May 15, 2010, from http://www.cnn.com/2010/TRAVEL/03/03/air.t raffic.child/index.html

[2] Bachman, J. (2010, April 26). The New York Air Traffic control kid and aviation professionalism. Bloomsberg Business week. Retrieved May 15, 2010 from, http://www.businessweek.com/lifestyle/traveler s_check/archives/2010/03/jfks_air_traffi.html

[3] Bentley, R., Hughes, J. A., Randall, D., Rodden, T., Sawyer, P., Shapiro, D. et al. (1992). Ethnographically informed systems design for air traffic control. CSCW 92 Proceeding. CSCW Research Centre, Computer and Sociology Departments, Lancaster University, UK, p. 123-129.

[4] Brockman, J., and Minton, T. (2010, March 3) Double Trouble: Two children took to JFK Controls. CNBC New York. Retrieved May 15, 2010 from, http://www.nbcnewyork.com/news/localbeat/CHILDS-PLAY-AT-JFK-86174177.html
[5] Brown, J. S. \& Duguid, P. (2000). The social life of information. Boston: Harvard Business School Press.

[6] Dewey, J. (1986). Logic: The theory of inquiry. In J. A. Boydston (Ed.), John Dewey: The later works, 1925-1953 (Vol. 12: 1938). Carbondale and Edwardsville: Southern Illinois University Press. (Original work published 1938).

[7] Drazenovich, D. A. (2007). A study on the use of radar data in air traffic control. Robert Morris University, UMI Number: 3328713.

[8[ Drazenovich, D. A., \& Skovira, R. J. (2009). "Roman 41, Roger...what is your position?": The infoscape of air traffic controllers. Issues in Information Systems, X(2), 421-429.

[9] Eco, U. (1976). A theory of semiotics. Bloomington, IN: Indiana University Press.

[10] Ellingson, J. (2009). Managing risk with a cultural perspective. Risk Management, 56(10), $50-53$.

[11] Federal Aviation Administration (2009). Air Traffic Plans and Publications, March 15, 2009, from, http://www.faa.gov/airports_airtraffic/air_traffi c/publications/

[12] Federal Aviation Administration (2006). Order 7110.65R Air Traffic Control. February 16, 2006, change 1 August 3, 2006.

[13] Federal Aviation Administration (2010). Order 7110.65T Air Traffic Control. February 10, 2010.

[14] Federal Aviation Administration (2005). Order 3120.4L Air Traffic Technical Training. June 22, 2005.

[15] Federal Aviation Administration (2002). Order 7210.56C Air Traffic Quality Assurance. August 15, 2002, Change 2, July 20, 2009.

[16] Goffman, E. (1974). Frame analysis: An essay on the organization of experience. Cambridge: Harvard University Press.

[17] Grabowski, M., \& Roberts, K. H. (1999). Risk mitigation in virtual organizations. Organization Science, 10(6), 704-721.

[18] Grabowski, M., \& Roberts, K. (1997). Risk mitigation in large-scale systems: Lessons from high reliability organizations. California Management Review, 39(4), 152-162.

[19] Hall, E. T. (1989). Beyond Culture ( $3^{\text {rd }}$ ed.). New York: Anchor Books.

[20] Helmreich, R. L. (2000). On error management: lessons from aviation. British Medical Journal, 320(7237), 781-785. 
[21] Hofstede, G. (2006). What did GLOBE really measure? Researchers' minds versus respondents' minds. Journal of International Business Studies, 37, 882-896.

[22] Hofstede, G. (2002). Dimensions do not exist: A reply to Brendan McSweeney. Human Relations, 55(11), 1355-1361.

[23] Hofstede, G. (2001). Culture's consequences: comparing values, behaviors, institutions, and organizations across nations, $2 e$. Thousand Oaks, CA: Sage.

[24] Hofstede, G. (1997). Cultures and Organizations: Software of the Mind. New York: McGraw-Hill.

[25] Hughes, J., King V., Rodden, T., \& Andersen, H. (1994). Moving out of the control room: Ethnography in system design. CSCW Research Centre, Computer and Sociology Departments, Lancaster University, UK, p. 429439.

[26] Klein, R. L., Bigley, G. A., \& Roberts, K. H. (1995). Organizational culture in high reliability organizations: An extension. Human Relations, 48(7), 771-793.

[27] Lakoff, R. T. (2000). The language war. Berkeley: University of California Press.

[28] March, J. G., \& Olsen, J. P. (1979). Ambiguity and choice in organizations, $2 e$. Bergen, Norway: Universitetsforlaget.

[29] Nolan, M. S. (1999). Fundamentals of air traffic control ( $1^{\text {st }}$ ed.). Pacific Grove: Brooks/Cole Wadsworth.

[30] Roberts, K. H. (1990). Managing high reliability organizations. California Management Review, 32(4), 101-113.

[31] Skovira, R. J. (2005). New lecture notes: Ethnography of information systems. Unpublished manuscript, Robert Morris University at Pittsburgh.

[32] Skovira, R. J. (2005). Specifying an idea for inquiry about uncertainty avoidance models among Slovak IT professionals in the information society. Proceedings of INFOS 2005, Bratislava, 141-148.

[33] Skovira, R. J. (2004). Using informational landscape as a model to understand information use and design within organizations. Issues in information Systems, V(1): 308-314.

[34] Spradley, J. P. (1979). The ethnographic interview. Belmont: Wadsworth

[35] Spradley, J. P. (1980). Participant observation. United States: Wadsworth.
[36] Spradley, J. P., \& McCurdy, D. W. (1972). The cultural experience: Ethnography in complex society. 